University of Washington Tacoma

UW Tacoma Digital Commons

Social Work \& Criminal Justice Publications

Social Work \& Criminal Justice

$10-2007$

\title{
Experiences of Stigma in Older Adults Living With HIV/AIDS: A Mixed-Methods Analysis
}

Charles Emlet

University of Washington Tacoma, caemlet@uw.edu

Follow this and additional works at: https://digitalcommons.tacoma.uw.edu/socialwork_pub

Part of the Social Work Commons

\section{Recommended Citation}

Emlet, Charles, "Experiences of Stigma in Older Adults Living With HIV/AIDS: A Mixed-Methods Analysis" (2007). Social Work $w$ Criminal Justice Publications. 4.

https://digitalcommons.tacoma.uw.edu/socialwork_pub/4

This Article is brought to you for free and open access by the Social Work \& Criminal Justice at UW Tacoma Digital Commons. It has been accepted for inclusion in Social Work \& Criminal Justice Publications by an authorized administrator of UW Tacoma Digital Commons. 


\title{
Experiences of Stigma in Older Adults Living with HIV/AIDS: A Mixed-Methods Analysis
}

\author{
CHARLES A. EMLET, Ph.D., M.S.W.
}

\begin{abstract}
Older adults are increasingly becoming impacted by HIV disease, both as newly infected individuals and as long-term survivors of HIV/AIDS living into older age. HIV-related stigma impacts the quality of life of all persons with HIV/AIDS. However, little is know about HIVrelated stigma in older adults because many studies do not include older subjects or ignore age as a variable. This mixed methods study examined the experiences of HIV-related stigma in a sample of 25 older adults with HIV/AIDS from the Pacific Northwest. Quantitative methods measured HIV-stigma and depression, while in-depth qualitative interviews captured the lived experiences of these individuals. Stigma was positively and significantly correlated with depression $(r=0.627, p=0.001)$ and stigma was found to be significantly higher in African American, as compared to white informants $\left(\chi^{2}=4.16, p=0.041\right)$. Qualitative interviews yielded 11 themes that correspond to the four categories constructed in the stigma instrument. Rejection, disclosure concerns, stereotyping, protective silence and feeling "other" were all common experiences of these individuals. HIV stigma should be routinely assessed when working with older, HIV infected clients and interventions should be tailored to the individual experiences of stigma.
\end{abstract}

\section{INTRODUCTION}

$\mathbf{T}$ HE USE OF highly active antiretroviral therapies (HAART) has extended survival for persons living with HIV / AIDS and allows individuals, as never before, to live into later life. While adults over the age of 50 will continue to become newly infected with HIV, the number of long-term survivors will also continue to increase. Surveillance data from the Centers for Disease Control and Prevention (CDC) reflect these trends. The estimated number of persons, age 50 and over, living with AIDS in the United States increased by nearly $60 \%$ in a period of 4 years from 65,655 in 2001 to 104,261 in 2004. ${ }^{1}$

HIV stigma is a critical issue that impacts the quality of life of all persons with HIV disease. A recent report by the Health Resources and Services Administration (HRSA) suggest that stigma defines "virtually every level of society's reaction to HIV/AIDS,"2(p16) yet mostly goes unnoticed and unchallenged. HIV stigma has been found to have deleterious affects on both the behaviors and the self-image of stigmatized persons. Behaviorally, stigma has been found to negatively affect HIV test-seeking behavior, willingness to disclose HIV status, health-seeking behavior, quality of health care, and social support. ${ }^{2}$ Studies have found HIV stigma to be associated with various interpersonal and psychosocial issues such as feelings of shame and guilt, ${ }^{3,4}$ fear and anger, ${ }^{3,4}$ mental 
strain, ${ }^{5}$ and feelings of self-loathing. ${ }^{3,6,7}$ HIV stigma has also been associated with clinical symptoms of depression in a variety of HIV-infected populations. ${ }^{4,8-12}$ The impact of HIV-related stigma may be long lasting. In a recent study of stigma among Asian and Pacific Islanders in the United States, Kang and colleagues $^{13}$ found that the harmful effects of stigma, including social rejection and isolation, were sustained over a period of 2 years.

While the numbers of older adults living with HIV/AIDS continues to increase, the research on HIV stigma has, for the most part, ignored this hidden population of the AIDS pandemic. The purpose of this paper is to examine, through mixed-methods research, HIV stigma in 25 adults, age 50 and older, who are living with HIV / AIDS. As the HRSA publication suggests, "until stigma is named and challenged, little can be done to mitigate its effects."2(p16) While this statement applies to people of all ages impacted by HIV/AIDS, it is particularly relevant to older adults at this point in time.

\section{STIGMA THEORY AND RESEARCH}

HIV stigma is based on the theoretical work of Goffman ${ }^{14}$ who pioneered the concept of stigma, suggesting some characteristics spoil one's social identity. The discrediting attributes which Goffman described may take the form of physical deformity, blemishes of character, and tribal stigma. More recently, HIV stigma has been defined as prejudice, discounting, discrediting, and discrimination that are directed at people perceived to have HIV or AIDS. ${ }^{7}$ Although stigma is felt by persons diagnosed with a wide spectrum of diseases, four characteristics that are associated with higher levels of stigma are found with HIV/AIDS. These characteristics include: (1) diseases perceived to be the bearer's responsibility; (2) diseases that are associated with unalterable or degenerative conditions; (3) conditions perceived to be contagious; and (4) conditions that are readily apparent to others. ${ }^{5,7}$ Green and Platt ${ }^{5}$ suggest HIV stigma may be enacted or felt. Enacted stigma refers to individually or collectively applied sanctions such as discrimination or prejudice. Felt stigma, on the other hand, relates to feelings of shame, guilt, and the oppressive fear of enacted stigma. This conceptualization of HIV-stigma suggests the existence of a multidimensional construct that may manifest differently from individual to individual.

Our understanding of HIV- stigma in older adults, however, is limited by the fact that stigma research has typically not included older adults in sampling. ${ }^{3,4,5,15-18}$ For example, in one study of stigma and shame among individuals tested for HIV or gonorrhea, Fortenberry and colleagues ${ }^{18}$ excluded from their analysis all individuals over 59 years of age in order to "focus on the groups at greatest STD/HIV risk."18(p379) Other studies on HIV stigma may have recruited older persons but have neglected age as a variable in the analysis. ${ }^{19-21}$ A small number of studies on stigma have included older adults in the analysis or have focused specifically on older people. Lee et al. ${ }^{22}$ studied internalized HIV stigma in 268 men and women, including older adults ages 50 to 60.5 and found no significant difference in age between those with high and low levels of internalized stigma. In a recent study of 44 individuals age 50-plus and 44 younger adults ages 20-39 with HIV / AIDS, Emlet ${ }^{23}$ found 50\% of older adults reported they were ashamed of their illness sometimes or often, and 50\% stated they felt others were uncomfortable being around them, sometimes or often, because of their HIV disease. More than one quarter felt blamed by others for their illness. The proportion of younger adults with these feelings was slightly lower. Heckman et al. ${ }^{24}$ studied 83 persons over 50 with HIV disease and stigma was included along with depression and quality of life measures. HIV stigma was associated with cognitive affective symptoms of depression and increased barriers to health care. In a recent qualitative study of older adults ages 50-72, Emlet ${ }^{25}$ found the majority of informants were stigmatized by ageism as well as their HIV status.

\section{MATERIALS AND METHODS}

Participants, setting, and procedures

All study procedures were approved by the Institutional Review Board (IRB) at the Uni- 
versity of Washington. Participants $(n=25)$ were recruited from the local AIDS service organization (ASO), county public health, infectious disease clinics, and medical centers. In comparing the study sample to the overall client population of the ASO, women and African American elders were overrepresented. Approximately $28 \%$ of clients from the ASO are 50 years or older. Purposive sampling techniques were used, however, because of the relatively small number of potential participants and difficulty in identifying and locating participants. Thus, there was no attempt made to ensure the study sample was representative of the overall ASO client population. Because of the use of qualitative methods employing indepth interviews, a small sample size was deemed appropriate. ${ }^{26}$ Direct service staff, such as case managers, from agencies who agreed to recruit participants for the study identified potential participants. Selection criteria included being 50 years of age or older and having a diagnosis of HIV or AIDS. During their initial contact with potential respondents, providers would briefly describe the study, and referred subjects to the principal investigator (PI). Informed consents were signed at that time. Participants were compensated for their time with a payment of $\$ 25$. The vast majority of interviews (approximately 20), were conducted at the ASO with the remaining interviews completed at the PI's office located on the nearby university campus. Each respondent was interviewed one time with interviews lasting between 1-2 hours. Both quantitative and qualitative data were gathered during that interview. Information was gathered in three segments over the course of the interview. The interview segments included the gathering of demographic data, completion of standardized measures related to stigma and depression, and responses to two semi-structured interview questions. All participants were interviewed between November 2003 and December of 2004.

\section{Measures}

Sociodemographic variables. First, participants provided information on sociodemographic characteristics including age, gender, race and ethnicity, education, income, employment status, Medicaid eligibility, and HIV disease status. In addition to providing this material, participants were asked to supply a pseudonym (used throughout this document) that would be used for the remainder of the interview. This procedure insured confidentiality while personalizing conversations and subsequent reporting of qualitative data.

HIV stigma. Participants completed a 40item HIV stigma instrument developed and tested by Berger and colleagues. ${ }^{27}$ This scale consists of 40 questions and utilizes a 4-point, Likert-type scale (strongly disagree, disagree, agree, and strongly agree) that captures various aspects of HIV stigma. The range of possible scores for each item is 1 to 4 , therefore possible summated scores range from 40 to 160, with higher scores indicating greater stigma. The scale included four subscales. The personalized stigma scale measures the consequences of others knowing about one's HIV status including loss of friends, avoidance of others etc. The disclosure subscale includes items related to disclosing or keeping one's HIV status secret. The third subscale focuses on negative self-image and includes questions about feeling shame, guilt, and issues related to selfworth. Last, the public attitudes subscale included items about what "most people" think about HIV disease. Coefficient $\alpha$ for the scale have been found to be 0.96 for the overall scale and between 0.90 and 0.93 for subscales. Similar $\alpha$ were found in a recent study where the measure was administered to older adults. ${ }^{28}$

Depressive symptoms. Participants completed the Center for Epidemiological Studies Depression Scale (CES-D) ${ }^{29}$ The CES-D is a 20item scale designed to capture issues related to depressed mood. The scale contains 20 items. The minimum score for this scale is 0 with a maximum possible score of 60 . The cutoff identified for the CES-D is a score of $16 .^{30,31}$ The CES-D has been found to be useful in screening depression in older adults with HIV. ${ }^{32}$

Semistructured questions. The third segment of the interview consisted of two semistructured questions. The first question asked, 
"Could you tell me about a time that you felt discriminated against or mistreated because of being older and having HIV disease?" The second question asked, "What do you think society should know about being older and having HIV disease?"

\section{Analysis}

Data related to sociodemographic variables, HIV stigma, and depressive symptoms were analyzed using SPSS (version 13.0, SPSS Inc., Chicago, IL). All scales were scored according to the instructions provided by the author. The semistructured qualitative data were analyzed using open and axial coding methods, ${ }^{33}$ and a qualitative software package (HyperRESARCH 2.6, ResearchWare, Inc., Randolph, MA). Qualitative analysis software allows for the compact storage of transcription materials and HyperRESEARCH specifically assists with coding text, retrieval of coded text, categorization, and statistical analysis of the frequency of occurrence of codes. ${ }^{34}$

\section{RESULTS}

\section{Sample description}

The 25 participants ranged in age from 50 to 72 years $(\mathrm{M}=56.1$, standard deviation $[\mathrm{SD}]=$ 5.75). Seventeen $(68 \%)$ were male and $40 \%$ were people of color. All but 1 of the non-white participants was African American. Participants averaged 12.9 years of education. Six (24\%) had no educational degree, $15(60 \%)$ had completed high school, and 4 (16\%) held a college degree or higher. The majority (72\%) were retired, 6 were working part or full time, and 1 was unemployed. Fifty-two percent lived alone. Seven individuals lived with a partner or spouse, and of those, the length of cohabitation varied dramatically from 1 to 47 years. The vast majority, $76 \%$, had met criteria for an AIDS diagnosis. Sixty percent had been on Medicaid in the past year. Nine participants (36\%) had been exposed to HIV through men having sex with men and the same number identified heterosexual sex as their exposure risk. Four individuals were infected through injection drug use and one individual was exposed through contaminated blood products. Two had an unknown risk factor.

\section{Quantitative findings}

Stigma scores for the sample ranged from 54 to 141 with a mean of 94.32 (SD = 23.12). The internal consistency for this instrument was high with an overall $\alpha=0.96$. For subscales, $\alpha$ were also high ranging from 0.92-0.96. As the scale's total possible range of scores is $40-160$, these participants represented a wide range of experiences related to HIV stigma. Because each of the subscales in the stigma instrument contained a different numbers of items, index scores were calculated to compensate for these differences. Index scores were calculated by anchoring each item's rating scale at zero, then dividing the subject's subscale total by the range of possible scores for that subscale, which allows for the comparison across subscales. Figure 1 shows index scores for the four subscales: personalized stigma, 0.58; disclosure, 0.66 ; negative self-image, 0.53 ; and public attitudes, 0.60 . While internalized stigma was an important factor for these individuals, the higher scores on the disclosure and public attitude subscales suggest that enacted stigma was slightly more pronounced for the individuals interviewed in this study.

Table 1 provides data on the summated stigma score and subscale scores by age, gender, race, HIV status, and HIV risk. Because of the small sample size, the Mann-Whitney $U$ statistic was used to evaluate statistical differences in scores. Any tests were considered statistically significant if $p<0.05$.

Those 60 years and older had lower scores on all subscales and total stigma score compared to those 50-59 years. The differences, however, were not statistically significant. With regard to gender, men were found to have higher scores across all scales, but only on the personalized stigma subscale was the difference statistically significant $(z=-2.15, p=$ $0.031)$. The one area in which scores were consistently and significantly different was related to race. Non-whites had significantly higher scores, indicating greater stigma, on the personalized stigma scale $(z=--2.30, p=0.021)$, the disclosure scale $(z=-2.30, p=0.021)$, the 


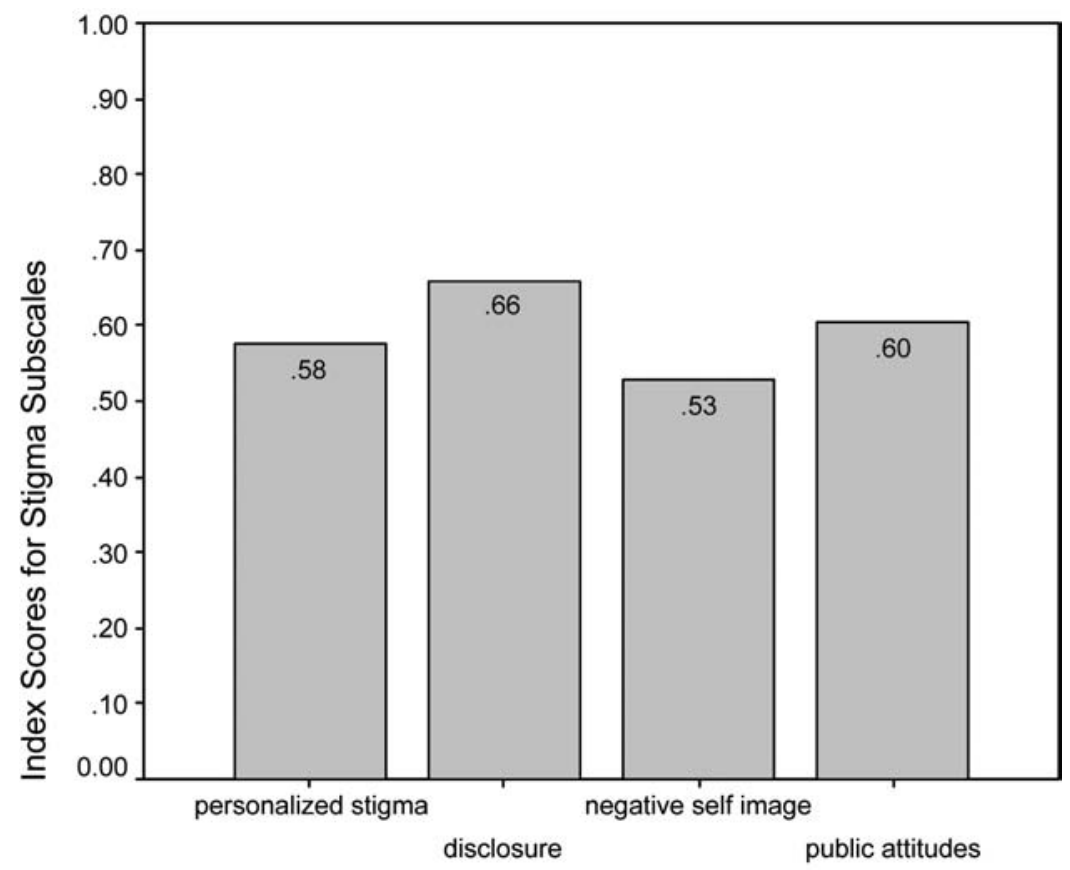

FIG. 1. Index scores on four HIV-related stigma subscales $(n=25)$.

negative self-image scale $(z=-2.89, p=$ $0.004)$, the public attitudes scale $(z=-2.58, p=$ $0.010)$ and the summated stigma score $(z=$ $-2.72, p=0.007)$. Respondents with AIDS had consistently lower scores in all instances than their counterparts without AIDS (HIV-posi- tive) (all not significant.) and no statistical differences were found across HIV risk factors.

CES-D scores for the sample ranged from zero to $50(\mathrm{M}=15.76$; $\mathrm{SD}=13.73)$. The internal consistency for the CES-D in this study was $\alpha=0.93$. Nine respondents $(36 \%)$ had CES-D

Table 1. Total Stigma Scores and Subscale Scores by Sociodemographic Variables

\begin{tabular}{|c|c|c|c|c|c|}
\hline & $\begin{array}{l}\text { Personalized } \\
\text { stigma }\end{array}$ & Disclosure & $\begin{array}{l}\text { Negative } \\
\text { self-image }\end{array}$ & $\begin{array}{l}\text { Public } \\
\text { attitudes }\end{array}$ & $\begin{array}{c}\text { Total stigma } \\
\text { score }\end{array}$ \\
\hline \multicolumn{6}{|l|}{ Age } \\
\hline $50-59(n=19)$ & 42.84 & 26.68 & 28.47 & 49.47 & 96.84 \\
\hline $60(n=6)$ & 37.00 & 25.33 & 24.00 & 44.33 & 86.33 \\
\hline \multicolumn{6}{|l|}{ Gender } \\
\hline Male $(n=17)$ & $44.41^{\mathrm{a}}$ & 27.52 & 28.70 & 50.29 & 98.82 \\
\hline Female $(n=8)$ & 35.12 & 23.87 & 24.62 & 43.87 & 84.75 \\
\hline \multicolumn{6}{|l|}{ Race/ethnicity } \\
\hline White $(n=15)$ & 37.20 & 23.66 & 23.93 & 43.73 & 84.73 \\
\hline Non-white $(n=10)$ & $47.80^{\mathrm{a}}$ & $30.40^{\mathrm{a}}$ & $32.60^{\mathrm{b}}$ & $55.00^{\mathrm{b}}$ & $108.70^{\mathrm{b}}$ \\
\hline \multicolumn{6}{|l|}{ HIV status } \\
\hline $\operatorname{HIV}(n=6)$ & 42.66 & 29.83 & 28.00 & 50.50 & 99.00 \\
\hline $\operatorname{AIDS}(n=19)$ & 41.05 & 25.26 & 27.21 & 47.52 & 92.84 \\
\hline \multicolumn{6}{|l|}{ HIV risk } \\
\hline $\operatorname{MSM}(n=9)$ & 39.77 & 25.55 & 26.44 & 46.44 & 91.11 \\
\hline Heterosexual $(n=9)$ & 43.55 & 27.44 & 29.00 & 49.66 & 98.11 \\
\hline IDU $(n=4)$ & 41.50 & 30.00 & 29.25 & 51.75 & 100.50 \\
\hline Other $(n=3)$ & 40.00 & 20.22 & 23.00 & 44.66 & 84.33 \\
\hline
\end{tabular}

MSM, men having sex with men; IDU, injection drug use.

a $p<0.05$.

$\mathrm{b}_{p}<0.01$. 
scores above 16 , which is a commonly used cutoff for risk of depression. $\chi^{2}$ tests were conducted to determine if any sociodemographic characteristics were associated with depression. HIV status and risk did not account for any differences in meeting the clinical cutoff for depression. Eight men had CES-D scores above the cutoff while only one female had scores above the cutoff. Non-whites were significantly more likely to exceed the clinical cutoff for depression than whites $(60 \%$ versus $20 \%) \chi^{2}(1$, $n=25)=4.16, p=0.041$.

CES-D scores were placed in a correlation equation with the summated stigma score and all subscale scores in order to identify significant associations between various aspects of stigma and depression. Higher scores on the CES-D were positively correlated with all stigma subscales and overall score. Statistically significant correlations were found with personalized stigma $(r=0.668, p=0.000$ [Exact $p$ values past three decimals are not available due to limitations in the statistical software]), negative self-image $(r=0.709, p=0.000)$, public attitudes $(r=0.573, p=0.003)$, and the overall scale $(r=0.627, p=0.001)$.

\section{Qualitative findings}

The mixed-methods approach provides opportunities to cross-validate findings (convergence) or to generate complementary findings. ${ }^{35}$ Through the use of a standardized open-ended interview format, ${ }^{26}$ individual experiences of stigma among this sample of older, HIV-infected adults were captured. The audiotapes of each completed interview were transcribed verbatim. The written transcripts were then reviewed by the PI and a research assistant for accuracy by listening to the tapes while rereading the transcripts. After each transcript was reviewed for accuracy, a process of open coding was undertaken. Open coding is designed to "open up the text and expose thoughts, ideas and meanings contained therein."33(p102) Initially, the data were opencoded line by line where the interviewees comments were broken down into specific concepts relevant to stigma or discrimination. Transcripts were examined for ideas, events, and experiences relevant to HIV stigma. This process produced a total of 107 relevant codes. These 107 codes were both researcher labeled as well as in vivo codes taken directly from the language of respondents.

Once this process was completed, and a list of codes developed, focused coding was used as categories were elaborated on, collapsed, or eliminated. ${ }^{34}$ Final coding and analysis was completed using the qualitative software package (HyperRESARCH 2.6) and resulted in the model seen in Figure 2. The qualitative analysis ultimately identified 11 themes which fit into the framework of subscales from the original instrument.

\section{THEMES}

\section{Personalized stigma}

Rejection. The personalized stigma scale measures the consequences of others knowing about one's HIV status including loss of friends, avoidance of others, etc. Three themes identified in the qualitative data were consis-

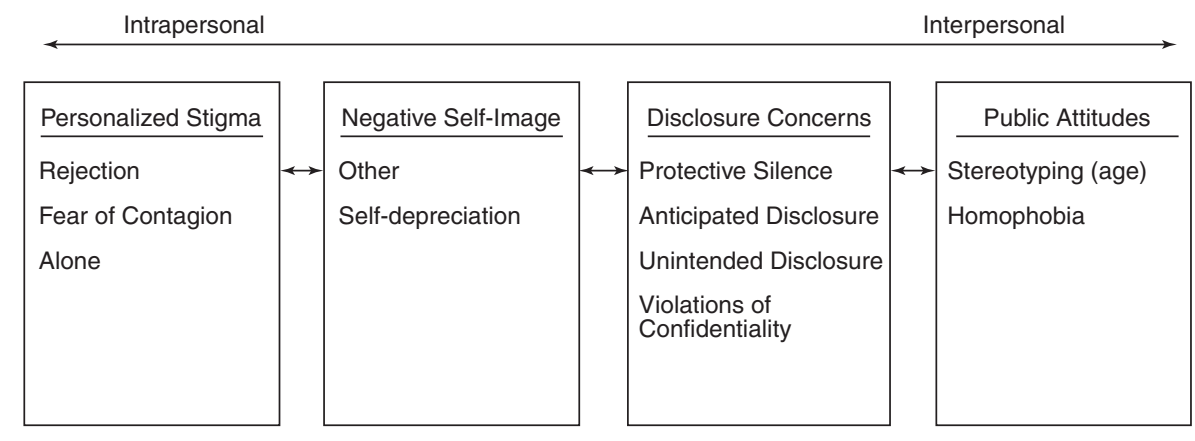

FIG. 2. Model of qualitative themes as relates to HIV stigma subscale. 
tent with this category. First, feelings of rejection were a common theme that emerged from the qualitative data. Respondents experienced rejection in formal and informal relationships among family, friends, church members, service providers, and potential lovers/partners. Fifty-six percent of the individuals $(n=14)$ interviewed shared experiences that were coded as rejection. Cricket (age 53) was rejected by her family. "My brothers found out and they was just like distanced from me for awhile ... I'd say for about 3 years." Steve (age 51) shared, "If I meet a girl or something and I want to be close to her, then I would have to tell her. She'll usually say forget it." Paul (age 53) recounted rejection by his religious community. "It'd gotten around the church that I'm HIV positive. I find myself sitting and eating a piece of cake and drinking punch on one whole aisle of chairs by myself, no one sitting next to me, no one wanting to talk to me."

Fear of contagion. Forty percent of respondents $(n=10)$ experienced what was ultimately labeled fear of contagion. This label was given to a specific form of rejection that had at its root fear of HIV and paralleled the description in the stigma scale of feeling others wanted them quarantined. Ohms (age 56) told of his experience with his physician after hip surgery.

In December of last year I had another total hip replacement surgery. And my doctor got stuck while performing the surgery and when I went for my follow-up treatment it was one of the first things be brought up. That was the first time I felt somebody wanted to back away from me. I felt like he doesn't what to treat me, you know, I felt that I needed to apologize for it-for him getting stuck.

Alex (age 51) recounted how after learning of his HIV diagnosis, several of this racketball partners no longer wanted to play racketball with him.

I have friends that I go to the gym with and do those kinds of things [racketball and contact sports] with. Some of them, a couple of them, don't want to do that anymore because they are fearful you know, the contact or whatever.

Alone. Being alone and socially isolated was also a recurrent theme related to person- alized stigma. Forty percent $(n=10)$ talked about issues of being alone. Louis (age 64) told about the loneliness he experiences as a result of AIDS.

To be old and live all alone in your little mobile home, I don't have a boyfriend, I don't have a girlfriend, I don't have a partner you know. I cold drop dead in my house and no one might know about it for 3 weeks.

Juanita (age 51) said, "It's lonely sometimes, it really is. I don't have any good friends because I don't trust people."

Negative self-image

Other. The concept of negative self-image was designed to capture feelings of shame, guilt, and self-depreciation related to HIV/ AIDS. The qualitative data support the position that these are real and common experiences in the lives of older adults with HIV/AIDS. A commonly expressed feeling was associated with being "other" or apart from the rest of society as a result of HIV. Eight individuals, or $32 \%$ of respondents expressed these feelings. While this did not always necessitate feeling less than others without HIV, it did communicate the barriers that exist and sets one apart. Wayne (age 59) said, "I kind of feel I'm radioactive." Mary (age 55) talked about the barrier her HIV disease created with the rest of society. She shared "whenever you have something that you can't share, it's a wall, I don't like that." For some of the respondents the feeling of "other" came not only from having HIV / AIDS, but being older. In talking about how younger gay men feel about aging, Terry (age 51) discussed that sense of other because of age. "I think most of the time they [younger men] just want to deal with their own peopletheir own age group, you know, you feel like an outcast." Another way in which feeling "other" manifested was the sense that people did not understand or recognize HIV as a disease that impacts older people. Juanita (age 51), at he beginning of her interview expressed this when she shared, "when I saw your sign outside, I thought, I was so happy to see that finally, finally somebody's addressing our needs." 
Self-depreciation. Some respondents $(n=2)$ expressed serious feelings of low self-esteem and lack of self worth related to their HIV disease. Juanita, for example said "I don't feel like, I don't have anything good to offer this person cause I'm just, I'm, I'm like run down baggage is what I'm sayin', you know." Cricket shared that, "For a long time I was afraid no one would want to do anything, you know, or hang out with me or start talking to me."

\section{Disclosure concerns}

Protective silence. The disclosure concern subscale focused on issues of telling others (about one's HIV), their real or anticipated reaction, and the fear of forced disclosure by other people. Protecting self through nondisclosure or silence about HIV / AIDS was a consistent vehicle used by these individuals. Sixty percent $(n=15)$ of the respondents talked about not telling other as a protective measure against potential stigma and discrimination. At age 72 , Eric is very protective of who knows about his HIV. He shared "I would rather get run over by a truck then die of AIDS. That's what I'm hoping for. I'm hoping that nobody else finds out about the AIDS." Mary lives with her parents and has not disclosed to them. She said "I just keep thinking I'm going to outlive them. I can't see a good reason to tell them." The extent and duration that protective silence was used is exemplified by Louis who, in the course of our interview shared that he had disclosed his HIV status to less than six people in 9 years.

Anticipated disclosure. While many of the individuals interviewed protected themselves from stigma through silence, eight informants (32\%) expressed the fear (often coupled with a need) of sharing their HIV status with others. For some, telling friends or family could open up the potential for social support. It could, however, backfire and result in stigmatization. The interviews revealed a period between protective silence and disclosure where the risks and benefits were contemplated. Taleef (age 50) shared, "My biggest fear of all was telling my daughters bout it and the most important person was my Mom." For others, they anticipated the reaction of disclosure from potential sexual partners. Nolan (age 56) said, "You meet somebody and you're afraid, afraid to like somebody because if you like somebody, you know, you have to tell 'em and then you're afraid of what their reaction will be."

Unintended disclosure. Four respondents $(16 \%)$ discussed anxiety over unintentional disclosure. These accounts reinforced items in the subscale recognizing that not all disclosure of HIV status is voluntary or intentional. Individuals worried about others finding out in inadvertent ways. Nolan said, "some people are nosy and I can't afford to slip, let somebody see a bottle of pills or sumpin you know." Mary was concerned that her mother might look up her HIV medications in a "drug book" and find out about her diagnosis. People learned to be vigilant about concealing their HIV status until such time they would decide to disclosure.

Violation of confidentiality. Six of those interviewed $(24 \%)$ talked about the unwanted and unauthorized sharing of their HIV status by others. This violation of confidentiality came from various sources such as casual friends, but also from professionals. Steve recounts a situation in which a correctional officer violated his confidentiality while he was incarcerated. "The guard asked what I was taking all those medicines for. The nurse told the guard and the guard told my sister. Then everybody found out. I would have rathered [sic] told them myself." Louis talked about insensitive treatment, and perhaps discriminatory procedure, at the office of a medical provider.

So when I got there [to the medical clinic] they hand me my chart and I'd go see the blood pressure nurse, then I'd go see the nurse that draws blood, then I'd go see the doctor. I'd walk around with this big chart with this big sticker on it-HIV positive. Everyplace I went I was carrying this. I felt why don't they just tattoo my forehead.

\section{Public attitudes}

Stereotyping. The public attitudes subscale was intended to capture items associated with the attitudes of others related to discrimination and social discomfort with HIV. What the qual- 
itative data uncovered was beliefs and attitudes as much about ageism and homophobia as about fear and discomfort with HIV/AIDS. A major theme that emerged was ageist attitudes about aging, sexuality and sexual orientation. Comments experienced by approximately $40 \%$ of the respondents $(n=10)$ were associated with sexuality, aging, and HIV / AIDS. Some respondents spoke of how society expects older people to be more knowledgeable about the disease based solely on one's age. Christa (age 64) said, "In some cases I believe older people are held to a different standard, that, well, for crying out loud, you should have know better." This is particularly interesting since older adults did not come to maturity at a time when HIV existed, and in fact know less about HIV than younger adults. At the same time, however, others voiced puritanical beliefs that society still holds related to aging and sexuality. Juanita simply put it, "The fact we 50, we're old and somebody's grandma, it can't be you." Wayne shared, "There's a lot of people that go-'you're awfully old to have this disease.'" Some respondents experienced reactions from others, including service providers that had, at the root of the question feelings about aging and sexual orientation. For example, Louis, recounts going to the emergency room for HIVrelated symptoms. "The first nurse that saw me, she saw my chart that I filled out that I was HIV-positive, her very first questions was how did I get to be HIV positive. When I see the doctor, her first question was how did I get to be HIV positive."

Homophobia. Another arena where public attitudes had a negative impact surrounded sexual orientation or perceived sexual orientation. Three of the individuals interviewed $(12 \%)$ reported experiencing stigma related as much to sexual orientation as to HIV itself. Todd (age 63) accounts being ostracized by childhood friends. "We've not talked, but I'm thinking that the word is clearly out that I'm gay and have been forever. It's the only reason I can think of for them not having anything to do with me." Eric expressed concern about how friends might view him due to his sexual orientation. "I guess you do look for approval from some people-close friends. You don't want [them] to think less of you because of your lifestyle." One respondent expressed concern that others would make assumptions about his sexual orientation because of HIV disease. Alex said,

A lot of women my age or around my age, I mean their going to think that I am gay or bi or something, you know ... I'm concerned about what they feel because, after all, I want to be with them and get close to them.

\section{DISCUSSION}

The purpose of this study was to explore the experiences of HIV stigma in a population of older, HIV-infected adults. A mixed-methods approach was used in order to gain objective measures of stigma, while triangulating those findings with qualitative data gleaned from personal experiences. Objectively, these individuals had varied experiences of HIV stigma as evidenced by the range of scores on the HIV stigma scale. While gender and HIV exposure had limited impact on HIV stigma, race appeared to be an important factor. Those individuals who were predominately African American had significantly higher scores on all stigma subscales than their white counterparts. These findings are consistent with the limited research on aging, HIV and race. Brown and Sankar ${ }^{37}$ have suggested that despite historically greater support from family, older African Americans with HIV may face rejection from family, friends, and religious institutions because of the socially stigmatized behaviors associated with HIV transmission. Similarly, in his study of older men of color, Jimenez ${ }^{38}$ found that for them, having HIV/AIDS was rated very high as a stigmatizing condition.

While everyone interviewed scored above the minimum on the stigma instrument, it was important to examine the characteristics of those individuals who reported limited stigma. Six individuals had stigma scores at or below the 25th percentile. They were almost evenly split between males and females and by risk factor. There were, however, two outstanding patterns that emerged. First, all six of these individuals where white and all but one had received an AIDS diagnosis. The previous dis- 
cussion sheds some light on potential reasons for increased stigma among people of color. But what about diagnosis? An AIDS diagnosis being associated with lowered stigma is consistent with disease progression theory, ${ }^{39}$ which posits that with increased symptoms (such as with AIDS), anxiety and the need for social support may motivate disclosure. This is also consistent with the recent findings of Emlet $^{23}$ who found time since diagnosis significantly correlated with disclosure and negatively correlated with stigma in a sample of 88 adults between the ages of 30 and 71.

The quantitative findings suggest that a substantial proportion of individuals in this sample had CES-D scores indicative of depression. In fact, $36 \%$ of those interviewed had scores greater than the commonly recognized cutoff for depressive symptoms. These findings are consistent with other studies in HIVpositive populations. ${ }^{24,40,41}$ Quantitative results also demonstrate a strong correlation between stigma and depression, which is also supported by prior research. ${ }^{24}$ The findings reinforce the need for HIV practitioners and service providers to be diligent in assessing depression and stigma in populations of older, HIV-infected adults.

The both quantitative and qualitative findings support the position that HIV stigma is a multidimensional construct and can manifest in ways which are associated with internal processes such as personalized stigma and negative self-image, as well as processes that are socially intertwined such as public attitudes. For practitioners and advocates, these findings have important implications. Through the identification of the types of stigma the personal experiences, appropriate interventions can be tailored to the individual. Weiss and Ramakrishna ${ }^{42}$ have suggested that interventions designed to mitigate stigma must vary with the conditions being considered. For example, should one's experience of stigma be primarily intrapersonal, including negative self-image and personalized stigma, supportive and insight-oriented counseling approaches may be appropriate. While not targeting stigma specifically, Heckman and colleagues ${ }^{43}$ studied the impact of group intervention with HIV-infected older adults. Randomized into two groups, the researchers reported those receiving immediate group interventions reported fewer psychological symptoms and reduced depression symptoms from pre-intervention levels. Should the primary experience of stigma be one of discrimination, however, appropriate interventions may be one of advocacy; challenging the discriminatory practices of the perpetrators. Ramirez-Valles and Brown ${ }^{44}$ have documented that despite the obstacle of stigma, Latino men who became involved in community-level HIV-related activities discovered a sense of empowerment, self-esteem, and reciprocity. If stigma-mitigating activities are to be successful, people living with HIV / AIDS must be viewed as not only as recipients of services but equal partners. $^{2}$

The qualitative findings also suggest the issue of disclosure bridges intrapersonal and social processes. Individuals in this study discussed disclosure-related issues such as protective silence and anticipatory disclosure that were primarily intrapersonal. However, they also referred to interactions that had a social element to the process such as unintended disclosure and violations of confidentiality. What emerges from these data is how complex the process of disclosure is and the wide variety of ways in which disclosure occurs. The concept of self-protection from stigma through silence is consistent with the finding of Nokes and colleagues ${ }^{32}$ as well as Shehan et al. ${ }^{45}$ who both found older adults to be less willing to disclose their HIV status than younger adults.

The stereotyping experienced by many of the respondents suggests that society continues to hold ageist attitudes about aging, sexuality and sexual orientation. Barker ${ }^{46}$ has suggested that society's stereotyping of older adults as asexual and heterosexual is anything but rare and the experiences of these individuals bear this sentiment out. Several respondents talked of the ageist attitudes that exist in the gay community and how older gay men are ostracized. These findings parallel those of Schrimshaw and Siegal ${ }^{47}$ who found the gay community places a high value on youth and vitality, marginalizing older gay men. While different than stereotyping, these experiences of feeling apart from society are important to note. This is an area in which stigma my manifest differently 
with older adults. They are more likely subject to ageist stereotypes that can impact diagnosis (lowered clinical suspicion) as well as being ostracized by others in one's peer group.

An interesting inconsistency between the quantitative and qualitative data surrounded feelings of self-depreciation and depression. While $36 \%$ of the individuals interviewed had CES-D scores indicating some depression, far fewer voiced any direct sentiment of negative self-image and depreciation in the qualitative segment of the interviews. It is possible that this discrepancy supports the use of standardized assessment instruments when attempting to identify syndromes such as depression as open-ended interviews may not capture important aspects of such syndromes. Openended interviews run the risk of not addressing issues not brought to the table by the interviewee.

This study had several important limitations that must be acknowledged. One limitation related to the small sample size and recruitment from a limited geographical area. In addition, the use of staff to assist in recruitment may have influenced participation. The research protocol, however, had strict limitations on the script used by staff to avoid the potential for undue influence. Such recruitment strategies combined with small sample size limit the generalizability of these findings. A second ramification of the small sample size is the limits to the types of quantitative analysis that could be conducted. The sample size could not support analysis beyond the bivariate level and often required the use of nonparametric tests. Thus, while associations could be determined, causal linkages cannot. This research also sought to capture the lived experience of these individuals. One element of this study was to capture the personal accounts of stigma and discrimination resulting from HIV / AIDS. Thus, the accounts of these individuals were taken without question and no attempts were made to prove or disprove their encounters of stigma and discrimination. Finally, the fact that all participants were compensated with $\$ 25$ could have influenced the willingness for some individuals to participate. It is the belief of the PI that this compensation was sufficient to compen- sate subjects for their time. This was approved through a rigorous process of the IRB.

Both the qualitative and quantitative data from this study suggest that issues of stigma for older adults with HIV/AIDS are very real and prominent in their lives. HIV stigma carries the potential for considerable destructive power. As discussed earlier in this paper, the recent report from HRSA on stigma suggests that "until stigma is named and challenged" there is little we can do to begin to mitigate its effects. ${ }^{2(p 16)}$ It will be the responsibility to service providers, academics, researchers, and older adults themselves to work toward to elimination of societal views that perpetuate HIV stigma. Researchers must continue to study the effects of stigma among older adults with HIV/AIDS and well as learning more about protective factors that help in the management of this phenomenon.

\section{ACKNOWLEDGMENTS}

This research was supported by the National Institute of Mental Health, Grant No. 1 R03 MH69334-01., The author wishes to thank Drs. Kathy Nokes and Diane Zablotsky for their helpful comments on earlier drafts of the manuscript.

\section{REFERENCES}

1. Centers for Disease Control and Prevention. HIV / AIDS Surveillance Report for 2005. Atlanta, GA: Center for Disease Control, 2006;16.

2. Health Resources Services Administration. HIV/ AIDS Stigma: Theory, Reality and Response. Rockville, MD: Health Resources Services Administration, 2004.

3. Bennett MJ. Stigmatization: Experiences of persons with Acquired Immune Deficiency Syndrome. Issues Ment Health Nurs 1990;11:141-154.

4. Laryea M, Gien L. The impact of HIV-positive diagnosis on the individual, part 1: Stigma, rejection, and loneliness. Clin Nurs Res 1993;2:245-266.

5. Green G, Platt S. Fear and loathing in health care settings reported by people with HIV. Sociol Health Illn 1997;19:70-92.

6. Herek GM. AIDS and stigma. Am Behav Sci 1999;42: 1106-1116.

7. Herek GM, Mitnick L, Burris S. Workshop report. AIDS and stigma: A conceptual framework and research agenda. AIDS Public Policy J 1998;13:36-47. 
8. Crandall CS, Coleman R. AIDS-related stigmatization and the disruption of social relationships. J Soc Pers Relat 1992;9:163-177.

9. Hall BA. Overcoming stigmatization: Social and personal implications of the human immunodeficiency virus diagnosis. Arch Psychiatr Nurs 1992:VI:189-194.

10. Heckman T, Kochman A, Sikkema K. Depressive symptoms in older adults living with HIV disease: Application of the chronic illness quality of life model. J Ment Health Aging 2002;8:267-279.

11. Siminoff LA, Erlen JA, Lidz CW. Stigma, AIDS and quality of nursing care: State of the science. J Adv Nurs 1991;16:262-269.

12. Swendeman DT, Comulada WS, Lee M, RotheramBorus MJ. The impact of stigma on the adjustment of young HIV+ persons [Abstract ThPeE7916]. Paper presented at the XIV International AIDS Conference. Barcelona Spain: 2002.

13. Kang E, Rapkin BD, DeAlmeida C. Are psychological consequences of stigma enduring or transitory? A longitudinal study of HIV stigma and distress among Asians and Pacific Islanders living with HIV Illness. AIDS Patient Care STDs 2006;20:712-723

14. Goffman E. Stigma: Notes on the Management of Spoiled Identity. Englewood Cliffs, NJ: Prentice-Hall, 1963.

15. Clark H, Lindner G, Armistead L, Austin B-J. Stigma, disclosure, and psychological functioning among HIV-infected and non-infected African-American women. Women Health 2003;38:57-71.

16. Lee M, Wu Z, Rotheram-Borus MJ, Detels R, Guan J, Li L. HIV-related stigma among market workers in China. Health Psychol 2005;24:435-438.

17. Surlis S, Hyde A. HIV-positive patients' experiences of stigma during hospitalization. J Assoc Nurses AIDS Care 2001;12:68-77.

18. Fortenberry JD, McFarlane M, Bleakley A. Relationships of stigma and shame to gonorrhea and HIV screening. Am J Public Health 2002;92:378-381.

19. Crandall CS, Coleman R. AIDS-related stigmatization and the disruption of social relationships. J Soc Pers Relat 1992;9:163-177.

20. Varas-Díaz N, Serrano-García I, Toro-Alfonso J. AIDS related stigma and social interaction: Puerto Ricans living with HIV/AIDS. Qual Health Res 2005;15: 169-187.

21. Weitz R. Living with the stigma of AIDS. Qual Sociol 1990;13:23-38.

22. Lee RS, Kochman A, Sikkema KJ. Internalized stigma among people living with HIV-AIDS. AIDS Behav 2002;6:309-319.

23. Emlet CA. A comparison of HIV-stigma and disclosure patterns between older and younger adults living with HIV/AIDS. AIDS Patient Care STDs 2006; 20:350-358.

24. Heckman T, Kochman A, Sikkema K. Depressive symptoms in older adults living with HIV disease: Application of the chronic illness quality of life model. J Ment Health Aging 2002;8:267-279.
25. Emlet CA. "You're awfully old to have this disease:" Experiences of stigma and ageism in adults 50 years and older living with HIV / AIDS. Gerontologist 2006; 46:781-790.

26. Patton MQ. Qualitative evaluation and research methods, 2nd ed. Newbury Park, CA: Sage, 1990.

27. Berger BE, Ferrans CE, Lashley F. Measuring stigma in people with HIV: Psychometric assessment of the HIV stigma scale. Res Nurs Health 2001;24:518-529.

28. Emlet CA. Extending the use of the 40-item HIV stigma scale to older adults: An examination of reliability and validity. J HIV/AIDS Soc Serv 2007;6:43-54.

29. Radloff S. The CES-D scale: A self-report depression scale for research in the general population. Appl Psychol Measure 1977;1:385-401.

30. Pandya R, Metz L, Patton SB. 2005. Predictive value of the CES-D in detecting depression among candidates for disease-modifying multiple sclerosis treatment. Psychosomatics 2005;46:131-134.

31. Stephenson-Cino P, Steiner M, Krames L, Ryan LB, Huxley, G. Depression in elderly persons and its correlations in family practice: A Canadian Study. Psychol Rep 1992;70:359-368.

32. Nokes KM, Holzemer W, Corless I, et al. Health-related quality of life in persons younger and older than 50 who are living with HIV/AIDS. Res Aging 2000;22:290-310.

33. Strauss A, Corbin J. Basics of Qualitative Research: Techniques and Procedures for Developing Grounded Theory, 2nd ed. Thousand Oaks, CA: Sage, 1998.

34. Hesse-Biber S, Dupuis P. Testing hypotheses on qualitative data: The use of HyperRESEARCH computerassisted software. Soc Sci Comput Rev 2000;18:320328.

35. Padgett DK. Mixed methods, serendipity, and concatenation. In Padgett DK, ed. The Qualitative Research Experience. Belmont, CA: Thompson Brooks/ Cole, 2004:269-284

36. Lofland J, Lofland LY. Analyzing Social Settings: A Guide to Qualitative Observations and Analysis, 3rd ed. Belmont, CA: Wadsworth, 1995.

37. Brown DR, Sankar A. HIV/AIDS and aging minority populations Res Aging 1998;20:865-884.

38. Jimeniz AD. Triple jeopardy: Targeting older men of color who have sex with men. J Aquir Immune Defic Syndr 2003;33(Suppl 2):S222 -S225.

39. Serovich JM. A test of two HIV disclosure theories. AIDS Educ Prev 2001;13:355-364.

40. Bing EG, Burnam MA, Longshore D, et al. Psychiatric disorders and drug use among human immunodeficiency virus-infected adults in the United States. Arch Gen Psychiatry 2001;5:271-278.

41. Brown GR, Rundell J, McManis SE, Kendall SN, Zachary R, Temoshok L. Prevalence of psychiatric disorders in early stages of HIV infection. Psychosom Med 1992;54:588-601.

42. Weiss MG, Ramakrishna J. Stigma interventions and research for international health. Lancet 2006;367:536538. 
43. Heckman TG, Barcikowski R, Ogles B, et al. A telephone-delivered coping improvement group intervention for middle-aged and older adults living with HIV/AIDS. Ann Behav Med 2006;32:27-38.

44. Ramiraz-Valles J, Brown AU. Latino's community involvement in HIV/AIDS: Organizational and individual perspectives on volunteering. AIDS Educ Prev 2003; 15(Suppl A):90-104.

45. Shehan CL, Uphold CR, Bradshaw P, Bender J, Arce $\mathrm{N}$, and Bender B. To tell or not to tell: Men's disclosure of their HIV-positive status to their mothers. Fam Relat 2005;54:184-196.

46. Barker JC. Lesbian aging: An agenda for social research. In: Herdt G, de Vries B, eds. Gay and Lesbian
Aging: Research, and Future Directions. New York: Springer, 2004:29-72.

47. Schrimshaw EW, Siegel K. Perceived barriers to social support from family and friends among older adults with HIV/AIDS. J Health Psychol 2003;8:738752 .

Address reprint requests to: Charles A. Emlet, Ph.D., M.S.W. University of Washington, Tacoma 1900 Commerce Street, Campus Box 358425 Tacoma, WA 98402

E-mail: caemlet@u.washington.edu 